\title{
FENOLOGIA E PRODUTIVIDADE DA SORVA (COUMA UTILIS (MART.) MUELL. ARG.) NA AMAZÔNIA CENTRAL ${ }^{1}$
}

\author{
Martha de Aguiar Falcão ${ }^{2}$ \\ Charles R. Clement ${ }^{3}$ \\ João Batista Moreira Gomes ${ }^{3}$
}

\section{Recebido em 06/08/1999. Aceito em 10/05/2003}

\begin{abstract}
RESUMO - (Fenologia e produtividade da sorva (Couma utilis (Mart.) Muell. Arg.) na Amazônia Central). A sorva ou sorvinha (Couma utilis (Mart.) Muell. Arg., Apocynaceae) é espécie amazônica de valor econômico, tanto como produtora de látex não elástico como de fruto comestível. O conhecimento de sua fenologia pode ajudar no planejamento e no manejo do plantio, bem como na comercialização dos frutos. Dez árvores de sorva num plantio homogêneo (plantadas em 1980) foram observadas de 1984 a 1990. A floração iniciou-se em 1984, intensificando-se a partir de 1985, chegando a 8.000 flores por árvore em 1988. No período ocorreram duas safras importantes durante o ano, embora em 1989 tenham ocorrido três. Em quatro dos sete anos de observações, a safra maior ocorreu durante o período das chuvas, e nos outros anos ocorreu no início do período seco. O vingamento médio anual de frutos variou de $10 \%$ no primeiro ano (1984) até $25 \%$ em 1989. Em 1986, as 10 sorveiras produziram, em média, 2.500 frutos, com peso médio de $15,5 \mathrm{~g}$, permitindo uma estimativa de quase $40 \mathrm{~kg}$ de frutos/árvore/ano e 15t/ha, numa densidade de 400 plantas/ha.
\end{abstract}

Palavras-chave - fruticultura tropical, floração, frutificação, vingamento

\begin{abstract}
Phenology and yield of sorva (Couma utilis (Mart.) Muell. Arg.) in Central Amazonia). The "sorva" or "sorvinha" (Couma utilis (Mart.) Muell. Arg., Apocynaceae) is an Amazonian tree of minor economic importance, from which a non-elastic gum and edible fruits are obtained. Knowledge of its phenology can help plan plantation management and fruit commercialization. Ten "sorva" trees in a monoculture plantation (planted in 1980) were observed from 1984 to 1990 . Flowering started in 1984, became significant in 1985, and reached 8,000 flowers/tree in 1988. There were generally two important harvests during the year, although there were three in 1989. In four of the seven years of observations the main harvest occurred during the rainy season, in the others it occurred at the beginning of the dry season. Mean annual fruit set varied from 10\% in the first year (1984) to $25 \%$ in 1989. In 1986, the 10 sorva trees produced an average of 2,500 fruits, each weighing on average $15.5 \mathrm{~g}$, permitting yield estimates of nearly $40 \mathrm{~kg}$ of fruits/tree/year and $15 \mathrm{t} / \mathrm{ha}$ at a density of $400 \mathrm{plants} / \mathrm{ha}$.
\end{abstract}

Key words - tropical fruit culture, flowering, fruiting, fruit set

1 Auxílios: Convênio Universidade do Amazonas e Instituto Nacional de Pesquisas da Amazônia (1985-1990); Conselho Nacional de Desenvolvimento Científico e Tecnológico - CNPq (1997-1998)

2 Bolsa do Programa de Capacitação Institucional do INPA, modalidade DTI, apoio do CNPq. Av. Col. Teixeira, 386, Cond. Rio Tupana, Apto. 602-A, CEP 69030-481, Manaus, AM, Brasil. (mfalcao@internext.com.br)

3 Instituto Nacional de Pesquisas da Amazônia, INPA, C. Postal 478, CEP 69011-970, Manaus, AM, Brasil 


\section{Introdução}

A sorva ou sorvinha (Couma utilis (Mart.) Muell. Arg., Apocynaceae) é uma espécie amazônica de valor econômico, produtora de látex não elástico e de fruto comestível (FAO 1986; Villachica et al. 1996), além de ser uma belíssima árvore com potencial ornamental ainda inexplorado. É encontrada espontaneamente nas florestas da Amazônia Central e cultivada nos arredores de Manaus em sítios e quintais (Falcão \& Lleras 1981). A altura das árvores é variável; em áreas abertas cresce até $12 \mathrm{~m}$ e na floresta chega a atingir $20 \mathrm{~m}$. Suas inflorescências são corimbosas, inseridas nas axilas das folhas. As pequenas flores hermafroditas, gamopétalas, são róseas. Os frutos são pequenas bagas globosas (10-20g), suculentas, geralmente verdes, às vezes marrons quando maduros, encerrando várias sementes pequenas. A polpa do fruto é comestível, de sabor agradável. Os frutos são colhidos da árvore quando quase maduros e, freqüentemente, colocados em carbureto para amadurecerem por igual, e amarrados em forma de cachos contendo 20 a 25 frutos para serem comercializados. É muito comum encontrá-los a venda nas ruas de Manaus e nas margens das estradas ao redor da cidade. Ocasionalmente a polpa é usada para sorvetes, sucos e cremes (Falcão \& Lleras 1981; FAO 1986).

A árvore exsuda látex branco não elástico de todas as suas partes, que ainda possui valor comercial como matéria-prima na indústria de goma-de-mascar (chiclete) (Falcão \& Lleras 1981; FAO 1986; Cavalcante 1991; Villachica et al. 1996). A produção do látex da sorva na Amazônia alcançou 66.000t/ano na época pósguerra, provavelmente de todas as espécies de Couma misturadas, mas atualmente está ao redor de 1.000t/ano. Atribui-se esta queda na produção à forma de exploração predatória, pois as árvores são derrubadas para extração do látex, bem como pela substituição gradual do látex por sintéticos na indústria de chiclete. Por falta de manejo adequado, a espécie está quase em extinção econômica em muitas áreas de sua distribuição natural (Villachica et al. 1996).

Algumas tribos indígenas da Amazônia utilizaram mistura do látex da sorva com banana para combater a diarréia (Patiño 1963); outros usaram o látex da sorva com o óleo de rícino (Ricinus communis L.) como anti-helmíntico (Hoehne 1946). É ainda usado pelos indígenas e caboclos da região para calafetar canoas e embarcações, bem como para caiação das palafitas (Prance \& Silva 1975; Falcão \& Lleras 1981; Cavalcante 1991).

Wielgolaski (1974) definiu a fenologia como o estudo do efeito da periodicidade das condições climáticas, influenciado pelas condições edáficas e ecológicas em geral, sobre o ciclo biológico das plantas, especialmente sobre os órgãos reprodutivos e de crescimento vegetativo. O conhecimento da fenologia ajuda o planejamento do manejo do plantio e a comercialização dos frutos. Falcão \& Lleras (1981) relataram dois anos de fenologia em plantas reprodutivas na região de Manaus, detectando floração e frutificação por ano, com alguma dissincronia entre plantas. Villachica et al. (1996) relataram duas frutificações por ano, uma pequena, outra grande, na região de Belém. O objetivo deste trabalho foi observar a fenologia da sorva desde o início de sua fase reprodutiva até sua plena reprodução.

\section{Material e métodos}

Dez árvores de sorva num plantio homogêneo instalado ao final de 1980, na Estação Experimental de Fruticultura Tropical (EEFT) do INPA, Rodovia BR 174, km 41, Manaus, Amazonas, Brasil, foram escolhidas ao acaso. O germoplasma usado no plantio foi oriundo de matrizes cultivadas na periferia de Manaus.

O clima de Manaus foi definido como "Afi", no esquema de Köppen, com médias anuais de $2.419 \mathrm{~mm}$ de chuva, $26,7^{\circ} \mathrm{C}$ e $87,5 \%$ 
de umidade relativa do ar (Ribeiro 1976). Os dados climáticos (Fig. 1A) foram obtidos da Estação Meteorológica do Ministério de Agricultura, a $60 \mathrm{~km}$ da EEFT, e podem não ser exatamente iguais à precipitação que caiu na área de observações, mas são usados porque não existe outra sequência completa mais próxima da EEFT.

Ranzani (1980) classificou um solo adjacente ao do plantio como latossolo amarelo, textura média. Acredita-se, entretanto, que esta classificação e descrição possam ser usadas neste caso porque o plantio se encontra no mesmo platô e a menos de um quilômetro da trincheira usada por Ranzani.

As observações fenológicas foram realizadas semanalmente no período de janeiro/1984 a dezembro/1990 em três galhos escolhidos ao acaso e extrapolados para toda a árvore por regra de três com o número total de galhos de cada árvore, conforme Falcão et al. (1988). O vingamento foi estimado para cada pico de frutificação, comparando o número de frutos com o número de flores nos três meses anteriores, bem como em base anual. Em junho/1986, envolveu-se dez botões florais e flores em saquinhos de morim fino em cada árvore para determinar se as flores eram autofecundadas. Em abril/1986, foram retirados e pesados 20 frutos quase maduros de cada árvore. Os insetos visitantes foram capturados nos períodos de maior floração (fevereiro e junho/1986), e fixados e montados para posterior identificação.

\section{Resultados e discussão}

Floração - A floração iniciou-se, esporadicamente, aos três anos no campo, em 1984, quando 8 das 10 árvores iniciaram sua fase reprodutiva. Por serem árvores pequenas e na primeira floração, houve poucas flores e, conseqüentemente, poucos frutos (Fig. 1B). A partir de 1985, a intensidade de floração aumentou, chegando a quase 8.000 flores por árvore em 1988. Sempre ocorreu um pico de floração $\operatorname{logo}$ ao início do período chuvoso (dezembro a março), seguida por um pico menor (ou equivalente) ao final do período chuvoso até o início do período seco (maio a junho/ julho). A floração não foi sincronizada em todas às árvores.

Falcão \& Lleras (1981) observaram que a floração em árvores maduras ocorreu entre meados da estação chuvosa e início da estiagem em 1977 e 1978, com um pouco de variação entre anos, um pouco diferente do que foi observado neste trabalho entre 1985 e 1990, embora também tenha ocorrido no período chuvoso. Estes autores também observaram que a floração não foi sincronizada entre as árvores.

O período decorrido entre o aparecimento dos botões florais e a abertura das flores foi de 15 a 20 dias. As flores abrem pela manhã e fecham ao final da tarde, como também observado por Falcão \& Lleras (1981); nos dias muito nublados ou chuvosos a maioria das flores permanece fechada. No dia seguinte, tornam a abrir e fechar, o mesmo geralmente acontecendo no terceiro dia, se não chegam a ser fecundadas. No quarto dia as flores não fecundadas caem, embora algumas possam cair na tarde do terceiro dia. Quando fecundadas, a corola cai.

As flores envolvidas em saquinhos de morim não vingaram, sugerindo que não houve autofecundação ou que o micro-ambiente criado pelo saquinho prejudicou a flor.

Frutificação - Nossa concepção é que a frutificação inicia-se logo após a floração com o vingamento dos frutos, pois flores que não vingam caem logo, e os frutos maduros são colhidos (ou caem) após três meses. Como na floração, a frutificação foi inexpressiva no primeiro ano (1984). Normalmente ocorreram duas safras importantes durante o ano (Fig. 1B), embora em 1989 tenham ocorrido três. Em alguns anos a safra maior ocorreu no período chuvoso (1985, 1987, 1988, 1990); em outros, ocorreu no início do período de estiagem. Como 

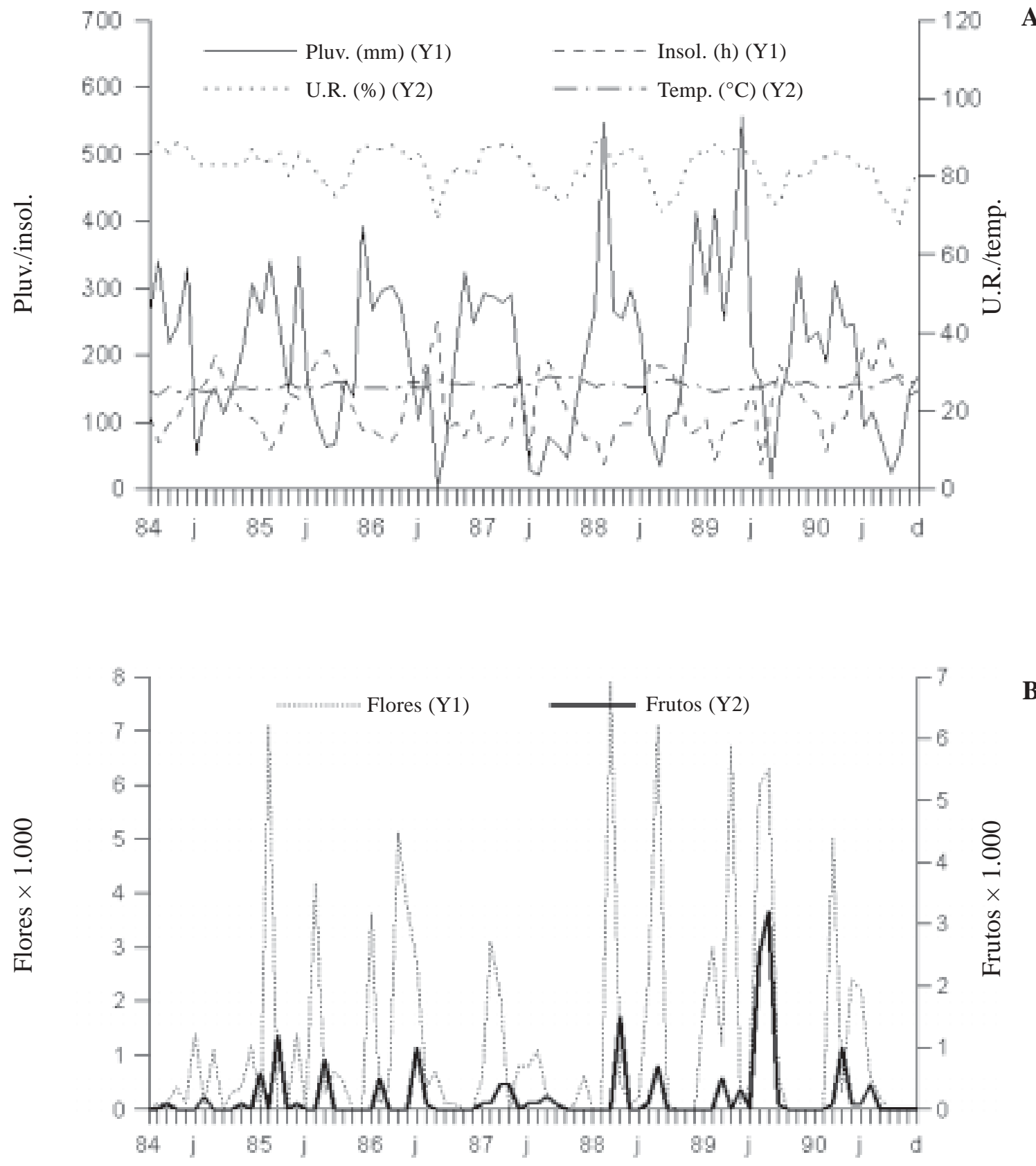

Figura 1. A. Dados climáticos de Manaus, AM, Brasil, de janeiro/1984 a dezembro/1990. B. Número médio mensal de flores e frutos da sorva (Couma utilis) durante o mesmo período. (O ano inicia na marca entre os digitos; " j" = junho; "d" = dezembro) 
no caso da floração, não existe sincronia perfeita na frutificação entre plantas.

Em árvores maduras, Falcão \& Lleras (1981) observaram safras no período de estiagem de 1977 e 1978, sendo que no presente estudo observou-se apenas uma safra ao final do período de estiagem (1985). Villachica et al. (1996) relataram a maior frutificação em Belém, Pará, em meados do período seco, ou seja, um pouco mais tarde que os picos do período de estiagem na Amazônia Central, e a menor, durante o período chuvoso, como observado aqui. Das fruteiras que florescem várias vezes durante o ano, como araçá-boi (Eugenia stipitata Mc Vaugh), abiu (Pouteria caimito Radlk.), ingá (Inga edulis Mart.), freqüentemente aparecem frutos tanto no período de estiagem, como no chuvoso (Falcão 1979; 1993).

Vingamento - $\mathrm{O}$ vingamento médio anual variou de $10 \%$ no primeiro ano (1984) até $25 \%$ em 1989, mas não aumentou de forma regular. $\mathrm{O}$ vingamento estimado por pico de frutificação variou de 0 a $39 \%$ (Fig. 2), sem relação aparente com a pluviosidade. Na época chuvosa de $1987 / 1988$, por exemplo, o vingamento foi menor que em 1988/1989, mesmo que a quantidade de chuva fosse similar (Fig. 2). Falcão et al. (1988) verificaram que a percentagem de vingamento alcançou $25 \%$ em araçá-boi adubado e apenas $12,5 \%$ em plantas não adubadas, enquanto que a maioria das fruteiras estudadas por Falcão $(1979 ; 1993)$ apresentaram vingamento menor que 5\%. Estas observações sugerem que a estratégia reprodutiva da sorva é diferente das fruteiras com baixo vingamento, que apresentam padrão identificado em outras regiões (Lloyd 1980; Browning 1985), em que a planta emite muitas flores para depois produzir frutos, conforme as possibilidades de seu estado nutricional.

Mudança foliar - A mudança foliar ocorreu sempre ao final da safra, tanto no período chuvoso como no seco; as folhas novas surgem antes da próxima floração. As plantas são semiperenifolias e houve dissincronia entre as plantas em termos de mudança foliar, como ocorreu na floração e na frutificação.

Insetos visitantes - Os insetos visitantes coletados foram os mesmos encontrados por Falcão \& Lleras (1981), embora as coletas tenham sido realizadas em áreas distantes. As

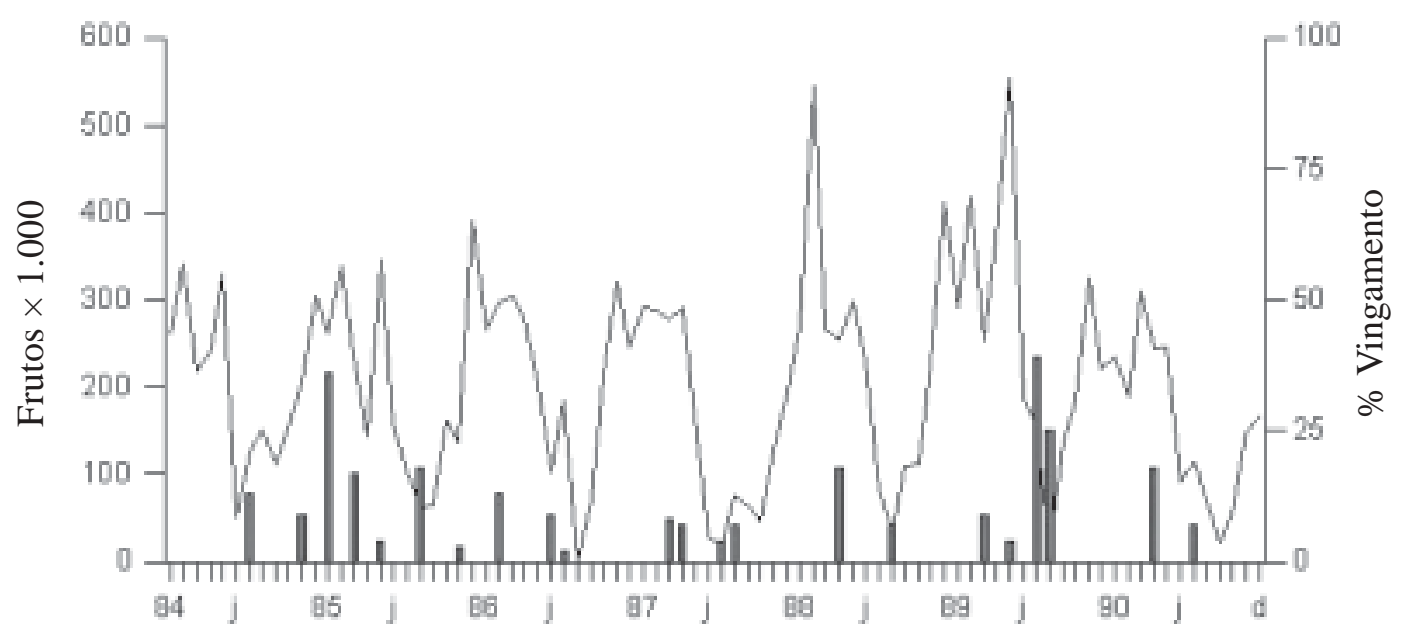

Figura 2. Vingamento estimado de frutos da sorva (Couma utilis) nos picos das frutificações (barras) e sua relação aparente com a pluviosidade mensal durante o período de 1984 a 1990 (linha). 
abelhas encontradas foram identificadas como Eulaema mocseryi Friese, E. nigrita Lepetier, Xylocopa frontalis Olivier, Epicharis sp. e Tetrapedia sp. Todas carregavam pólen da sorva nas suas patas. Supõe-se que as abelhas são as maiores polinizadoras, e que não há uma abelha específica para a sorva e sim um conjunto de polinizadores, como observado na maioria das fruteiras estudadas até agora (Falcão 1979; 1993).

Produtividade - Em 1986, as 10 sorveiras produziram, em média, 2.500 frutos, com peso médio de 15,5g (Tab. 1), permitindo uma estimativa de quase $40 \mathrm{~kg}$ de frutos/árvore/safra e 15t/ha numa densidade de 400 plantas/ha. Vale ressaltar que o germoplasma estudado não foi selecionado. Falcão \& Lleras (1981) estimaram produção de $30 \mathrm{~kg}$ de frutos/árvore, sugerindo que árvores novas são mais produtivas que árvores maduras, provavelmente devido à exportação de nutrientes com o tempo, embora as árvores maduras tenham maior porte que as novas. Villachica et al. (1996) relataram que a produção se inicia no sexto ano na Amazônia Ocidental, um pouco mais tardia que na Amazônia Central, embora eles não forneçam informações sobre o solo, que poderia influenciar na idade de produção.

Assim, pode-se concluir que sorva floresce principalmente no período chuvoso, apresentando geralmente duas safras por ano, uma no início das chuvas, e uma ao final das chuvas e início da estiagem. A produtividade ( 15t/ha) é

Tabela 1. Componentes da produtividade da sorva (Couma utilis) em Amazônia Central em 1986.

\begin{tabular}{|c|c|c|c|c|}
\hline \multirow[b]{2}{*}{ Árvore } & \multicolumn{2}{|c|}{ Frutos } & \multicolumn{2}{|c|}{ Produtividade } \\
\hline & $\begin{array}{l}\text { Peso } \\
(\mathrm{g})\end{array}$ & $\begin{array}{l}\text { Número/ } \\
\text { Árvore }\end{array}$ & $\begin{array}{c}\text { Árvore } \\
(\mathrm{kg})\end{array}$ & $\begin{array}{c}\text { Hectare } \\
\text { (t) }\end{array}$ \\
\hline
\end{tabular}

média \pm d.p. $\quad 15,4 \pm 3,5 \quad 2466 \pm 1549 \quad 38,3 \pm 27,5 \quad 15,3 \pm 11,0$ $\begin{array}{lllll}\mathrm{CV}(\%) & 22,7 & 62,8 & 71,8 & 71,9\end{array}$ $\begin{array}{llll}\text { mínimo } & 10,6 & 930 & 12,9\end{array}$

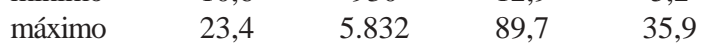

razoável para uma espécie não selecionada e pouco manejada. A fenologia de frutificação observada sugere que o produtor terá de fazer coletas freqüentes durante as safras para não perder produção e que a comercialização terá que ser igualmente eficiente.

\section{Agradecimentos}

Os autores agradecemos aos Drs. Norman Penny, ex-pesquisador do Departamento de Entomologia do INPA, João Camargo, da Faculdade de Medicina de Ribeirão Preto, São Paulo, e Pe. Jesus S. Moura, da Universidade Federal da Bahia, pela identificação das abelhas; à Profa. MSc. Rozana de Medeiros de Souza Galvão, pela colaboração na conferência e organização dos dados de campo; à Dra. Marlene F. Silva, pela correção do texto e sugestões oferecidas; ao técnico Sr. Damião Pereira Leocádio, pelo apoio no campo.

\section{Referências bibliográficas}

Cavalcante, P. B. 1991. Frutas comestíveis da Amazônia, $5^{\text {a }}$ ed. Edições CEJUP, Belém.

Falcão, M. de A. 1979. Aspectos fenológicos, ecológicos e de produtividade de algumas fruteiras cultivadas na Amazônia. Volume I. Ed. Calderaro \& Funcomiz, Manaus.

Falcão, M. de A. 1993. Aspectos fenológicos, ecológicos e de produtividade de algumas fruteiras cultivadas na Amazônia. Volume II. Univ. Amazonas, Manaus.

Falcão, M. de A. \& Lleras, E. 1981. Aspectos fenológicos, ecológicos e de produtividade da sorva (Couma utilis Muell. Arg.). Acta Amazônica 11(4): 729-741.

Falcão, M. de A.; Chavéz Flores, W. B.; Ferreira, S. A. N.; Clement, C. R.; Barros, M. J. B.; Brito, J. M. C. \& Santos, T. C. T. 1988. Aspectos fenológicos e ecológicos do araçá-boi (Eugenia stipitata McVaugh) na Amazônia Central. I. Plantas juvenís. Acta Amazônica 18(3-4): 27-38.

FAO. 1986. Food and fruit-bearing forest species. 3. Examples from Latin America. FAO Forestry Paper 44/3, Departament of Forestry. Rome, Italy.

Hoehne, F. C. 1946. Frutas indígenas. Instituto de Botânica, São Paulo. 
Patiño, V. M. 1963. Plantas cultivadas y animales domésticos en América Equinoccial. Tomo I: Frutales. Imprenta Departamental, Cali.

Prance, G. T. \& Silva, M. F. 1975. Árvores de Manaus. Instituto Nacional de Pesquisas da Amazônia, Manaus.

Ranzani, G. 1980. Identificação e caracterização de alguns solos da Estação Experimental de Silvicultura Tropical do Instituto Nacional de Pesquisas da Amazônia (INPA). Acta Amazônica 10(1): 7-41.
Ribeiro, M. N. G. 1976. Aspectos climatológicos de Manaus. Acta Amazônica 8(2): 229-233.

Villachica, H.; Carvalho, J. E. U.; Müller, C. H.; Diaz, S. C. \& Almanza, M. 1996. Frutales y hortalizas promisorios de la Amazonia. Tratado de Cooperación Amazonica, Lima.

Wielgolaski, F. E. 1974. Phenology in agriculture. Pp. 369-381. In: H. Lieth (ed.). Phenology and seasonality modeling. Chapman \& Hall, London. 